\title{
Cost-Effectiveness of UGT1A1*28 Genotyping in Preventing Severe Neutropenia Following FOLFIRI Therapy in Colorectal Cancer
}

\author{
Solen Pichereau ${ }^{1}$, Anne Le Louarn $^{2}$, Thierry Lecomte ${ }^{3,5}$, Hélène Blasco ${ }^{4,5}$, Chantal Le Guellec ${ }^{4,5}$ and Hélène Bourgoin ${ }^{1}$ \\ Departments of ${ }^{1}$ Pharmacy, ${ }^{2}$ Epidemiology, ${ }^{3}$ Gastroenterology and ${ }^{4}$ Biochemistry, Centre Hospitalo-Universitaire de \\ Tours, France. ${ }^{5}$ Université F. Rabelais de Tours, B.P. 3223, F-37032 TOURS cedex 1, France.
}

Received, July 5, 2010; Revised, November 16, 2010; Accepted December 23, 2010; Published December 29, 2010.

\begin{abstract}
Purpose. Functional polymorphisms of the UGT1A1 gene, particularly the UGT1A1*28 variant, are associated with the severity of the bone marrow suppression in patients with metastatic colorectal cancer receiving irinotecan. This study assesses the cost-effectiveness of screening for UGT1A1*28 polymorphism associated with primary prophylactic Granulocytes Colony Stimulating Factor in patients homozygous for the $* 28$ allele. The effectiveness was estimated based on the number of neutropenia avoided. Methods. This study was conducted from a hospital perspective. Relevant literature was analysed from 2000 to 2009 in order to select data and model parameters. We modelled a theoretical population treated with combined 5-fluorouracil, leucovorin and irinotecan (FOLFIRI) for metastatic colorectal cancer. A decision tree simulated the health outcomes, measured by the prevalence of neutropenic events for two strategies, with or without UGT1A1 genotype screening. The model incorporated direct hospital costs in 2006 and was validated with a sensitivity analysis. We calculated the cost-effectiveness ratio: $\mathrm{CE}=\Delta \mathrm{C} / \Delta \mathrm{E}=$ "genotyping" cost - "no genotyping" cost / number of febrile neutropenia avoided. Results. In the "genotyping strategy", the cost to avoid one febrile neutropenia event per 1000 patients treated was $€ 942.8$ to $€ 1090.1$. The sensitivity analysis showed a better CE ratio of $€ 733.4$ to $€ 726.6$ per febrile neutropenic event avoided. Conclusions. UGT1A1 genotype screening before irinotecan treatment is a cost-efficient strategy for the hospital. Systematic genotyping prior to chemotherapy, and administration of CSF in patients homozygotes for the $* 28$ allele allow to avoid 91 febrile neutropenias at an acceptable cost.
\end{abstract}

\section{INTRODUCTION}

Colorectal cancer is the third cancer in France with about 40000 new patients each year based on data of the Institut National de Veille Sanitaire (www.invs.sante.fr/). Irinotecan based chemotherapy is used in about $50 \%$ of metastatic colorectal cancers, thus concerning 5000-7000 patients per year. Irinotecan (CPT-11, Campto $\left.{ }^{\circledR}\right)$ is a camptothecin analogue used alone or in combination with other agents for palliative treatment of metastatic colorectal cancer (1). FOLFIRI, which consists of infusional 5fluorouracil, leucovorin, and irinotecan (180 $\mathrm{mg} / \mathrm{m}^{2}$ biweekly) as well as FOLFOX (oxaliplatin plus 5-fluorouracil and Leucovorin) are internationally accepted standard chemotherapies for this condition $(2,3)$. Irinotecan has been associated with dose-limiting toxicities, including myelosuppression and diarrhea, which have sometimes been severe. Febrile neutropenia (FN) frequently results in delays or reductions in chemotherapy doses, and may compromise outcome (4). Severe neutropenia with fever requires hospitalization and results in death in approximately $7 \%$ of such patients $(5,6)$.
The pharmacokinetics of irinotecan and its active metabolite $\mathrm{SN}-38$, are determined by numerous drug transporters and metabolizing enzymes (7). Pharmacogenetic studies have investigated the influence of genetic variation of these pathways on patient-to-patient variation of irinotecan pharmacokinetics and toxicity (8-10). The most consistent association was shown for a tandem repeat TA polymorphism $\left(-54(\mathrm{TA})_{6}>(\mathrm{TA})_{7} \mathrm{TAA}\right)$ in the TATA box of the promoter region of the UDP-glucuronosyltransferase 1A1 gene (UGT1A1), a key enzyme involved in the inactivation of $\mathrm{SN}-38$. The wild-type allele (UGT1A $1 * 1$ ) has six TA repeats, and the variant allele $(\mathrm{UGT} 1 \mathrm{~A} 1 * 28)$ has seven TA repeats. Patients who are homozygotes for the UGT1A1*28 allele (genotype 7/7) are exposed to higher plasma concentrations of $\mathrm{SN}-38$ due to impaired glucuronidation (9). Associations between the 7/7 genotype and hematologic toxicity were observed in various studies (11-13).

Corresponding Author: Chantal Le Guellec; Laboratory of Biochemistry; CHU Bretonneau de Tours; France; Email: leguellec@med.univ-tours.fr 
The absolute risk of toxic effects in patients with the $7 / 7$ genotype is up to $25 \%-40 \%$ in patients treated with intermediate doses $\left(150-250 \mathrm{mg} / \mathrm{m}^{2}\right)$ of irinotecan (14). As a result of these findings, it has been recommended that patients who are known to be homozygous for UGT1A $1 * 28$ receive lower starting dose of irinotecan (i.e. approximately $17 \%$ to $34 \%$ dose reduction) (15). However, there is still an uncertainty about the impact of irinotecan dose reduction on treatment efficacy. Prophylactic use of Colony Stimulating Factor (CSF) can reduce the risk of chemotherapy-induced neutropenia, thereby allowing a full dose of irinotecan to be used in the first cycle, and enabling the maintenance of higher chemotherapy dose intensity (16). The 2005 update Committee of the American Society of Clinical Oncology agreed unanimously that reduction in febrile neutropenia is an important clinical outcome that justifies the use of CSFs when the risk is approximately $20 \%$ and no other equally effective regimen to the use of CSFs is available. The Evaluation of Genomic Applications in Practice and Prevention (EGAPP) working group also recommended that pretreatment with CSF, without irinotecan dose reduction, may be considered for individuals who are homozygous for UGT1A $1 * 28$ and treated with FOLFIRI $(17,18)$.

The UGT1A1 7/7 genotype is relatively frequent in African (approximately 20\%) and Caucasian (approximately 10\%) populations (19). The a priori knowledge of UGT1A1 genotype can identify patients with high risk of severe neutropenia when treated with intermediate doses of irinotecan $\left(180 \mathrm{mg} / \mathrm{m}^{2}\right.$ in the FOLFIRI regimen) (14). The current US package insert recommends that a reduced initial dose should be considered in patients homozygous for UGT1A1*28 (20). Evaluation of the costeffectiveness of this pharmacogenetic approach may be interesting before its introduction into clinical practice in a university hospital. By developing a pharmacoeconomic model, our study aims to assess the cost-effectiveness of UGT1A1*28 polymorphism screening in patients with metastatic colorectal cancer prior to the initiation of irinotecan treatment. The sub-group of patients with genotype $7 / 7$ were undergoing primary FN prophylaxis with CSF, while the others received the standard treatment.

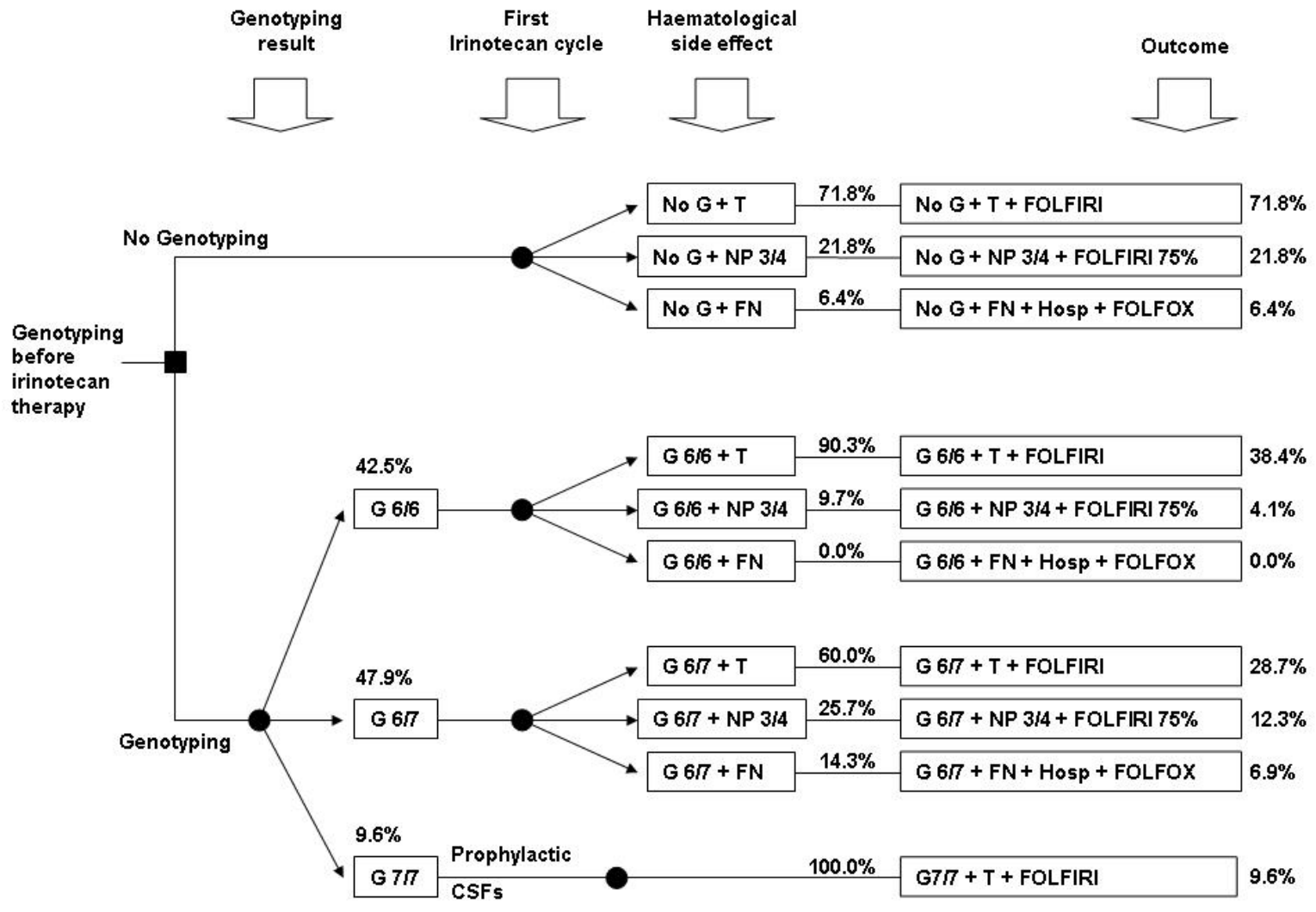




\section{METHODS}

A cost-effectiveness study was carried out by developing a decision analytic model from a hospital perspective. A decision tree estimated the costs and health outcomes of two different scenarios - genotyping or no genotyping of the UGT1A $1 * 28$ polymorphism - in patients receiving irinotecan for metastatic colorectal cancer. The decision tree parameters were established based on the analysis of the literature (frequency of genotypes and neutropenia under irinotecan chemotherapy) and the medical care practice in France.

\section{The decision tree}

The treatment options were displayed in a decision tree (figure 1). At a decision node ( $\square$ ), a treatment option must be selected and at a chance node $(\mathrm{O})$, a variety of outcomes may occur, each one with some degree of probability. The strategies compared succeeded to a decision node.

A case model was established based on a hypothetical cohort of 1000 patients receiving irinotecan therapy for metastatic colorectal cancer and undergoing standard haematological monitoring and therapeutic adaptation as in current practice. These patients received FOLFIRI every 2 weeks during day-care hospitalization. Published data indicate that neutropenia preferentially occurs during the first course of chemotherapy $(11,28)$. Thus, the study time frame began with the genotyping of patients, followed by the first chemotherapy and ended two weeks later with the second course of chemotherapy.

The decision tree compared 2 strategies indicated after the decision node, corresponding respectively to genotyping UGT1A $1 * 28$ polymorphism in patients or not. Patients in the "no genotyping strategy" (NoG) were exposed to three main haematological outcomes indicated by a chance node:

1 - Good tolerance (T) to treatment with no haematological side effect so that the patient can receive the same FOLFIRI dose 15 days later (corresponding to No G + T + FOLFIRI),

2 - Moderate haematological toxicity with grade 3 and 4 neutropenia (NP 3/4) requiring a modification of the second FOLFIRI course by decreasing the doses by $25 \%$ (corresponding to $\mathrm{NoG}+\mathrm{NP} 3 / 4+$ FOLFIRI 75\%) and eventually by delaying treatment until blood count normalisation,
3 - Severe haematological toxicity with febrile neutropenia (FN) requiring patient hospitalization and switch from FOLFIRI to FOLFOX regimen (oxaliplatine +5 -FU + folinic acid) (corresponding to No G $+\mathrm{FN}+$ Hosp + FOLFOX).

Regarding the "genotyping strategy" (G), patients were genotyped two weeks before beginning the FOLFIRI course. Homozygous patients for the UGT1A1*28 variant (G 7/7) received primary CSF prophylaxis at home after the first course of FOLFIRI. Therefore we considered them free of neutropenia and able to receive further FOLFIRI 15 days later (corresponding to $\mathrm{G}+\mathrm{T}+$ FOLFIRI). Patients with the genotypes $* 1 / * 1(\mathrm{G} 6 / 6)$ and $* 1 / * 28(\mathrm{G}$ 6/7), who were not receiving CSF after irinotecan therapy, were exposed to the same haematological outcomes as in the "no genotyping strategy" i.e. no haematological side effect (corresponding to $G$ $+\mathrm{T}+$ FOLFIRI), grade 3 and 4 neutropenia (corresponding to G + NP 3/4 + FOLFIRI 75\%), or febrile neutropenia (corresponding to $\mathrm{G}+\mathrm{FN}+$ Hosp + FOLFOX).

The estimated probabilities for each outcome were based on literature review, performed on Medline search. For the "no genotyping strategy", the haematological outcomes frequencies were obtained from the Tournigand et al French study (21). For the genotyping strategy, only studies carried out on Caucasian populations and indicating haematological outcomes (tolerance, NP $3 / 4$ and FN) for the three genotypes $(6 / 6,6 / 7$ and $7 / 7$ ) were retained in our model. Only one study corresponded to these criteria (13). The frequencies of each outcome and each genotype are indicated on the decision tree (figure 1). Multiplying the probability of each event by the frequency of each genotype gave the outcome probability.

\section{Economic analysis}

Our study is based on a cost-effectiveness analysis where the result is expressed as a ratio of cost per unit of effectiveness: the incremental cost-effectiveness ratio (ICER). It was calculated on our hypothetical cohort of 1000 patients. The costs and the effectiveness were estimated for the two strategies as indicated in the decision tree. Incremental Cost-effectiveness ratio was defined as follow:

$$
\text { Genotyping Cost - No Genotyping Cost }
$$

ICER $=-$
Genotyping Health Outcome - No Genotyping Health 


\section{The effectiveness}

The effectiveness was measured by the number of FN avoided in patients with the genotype *28/*28 (G 7/7) undergoing CSF prophylaxis, minus the difference in the number of FN occurring between the "genotyping strategy" and the "no genotyping strategy" (FN avoided in genotyping arm - (FN occuring in the genotyping arm - FN occuring in the no genotyping arm)).

\section{Cost estimates}

The direct costs concerned health consumption. They were identified using a hospital perspective, based on French hospital health financing and from the account department of the university hospital of Tours in 2006. The direct costs were the cost of the genotyping test, the cost of chemotherapy while day-care hospitalization and the cost of FN hospitalization which was variable, depending on associated comorbidities. The CSF cost was not taken into account as supplied by outpatient pharmacy and not by the hospital. The university Hospital of Tours does not have any analytic accountancy. Therefore the only costs available for hospitalization were standardised cost coming from of the hospital national cost study (year 2006). The hospitalization costs are classified by homogenous group of patients based on diagnoses, interventions, age, sex, discharge status, and the presence of complications or comorbidities, similar to DRGs (diagnosis-related group) in United-States.

\section{Cost of the genotyping test}

Genotyping was performed in the Biochemistry department of Tours University hospital. It consisted in DNA purification from blood samples, amplification of the promoter region with radiolabelled primers by use of PCR and determination of amplicon size by use of genescan analysis. Its actual cost was calculated including laboratory staff, reagents for genotyping and equipment redemption.

\section{Cost of chemotherapy}

Considering that all the patients were receiving the same first FOLFIRI course before haematological side effects could induce a change in their therapy, this cost was not retained in our study. Only the cost of the second chemotherapy course depending on haematological toxicity, was taken into account. The cost of chemotherapy included the cost of expensive anticancer drugs (irinotecan and oxaliplatine) in addition to the day-care hospitalization cost.

The standardised cost for chemotherapy daycare hospitalization was given by the $28 \mathrm{Z} 07 \mathrm{Z}$ homogenous group of patients. The actual cost of anticancer drug was estimated by the pharmacist accountancy for a standard patient measuring 170 $\mathrm{cm}$ and weighting $70 \mathrm{~kg}$, so corresponding to a body surface of $1,85 \mathrm{~m}^{2}$ for the FOLFIRI (irinotecan) and the FOLFOX (oxaliplatine) regimens.

\section{Cost of FN hospitalization}

The standardised cost for FN hospitalization was given by two homogenous group of patients who differed by the association of comorbidities (16M04W : severe cytopenia affections deficiency, age 18 to 69 years with comorbidities or age more than 69 years) or not $(16 \mathrm{M} 04 \mathrm{~V}:$ severe cytopenia affections without comorbidity, age 18 to 69 years). Therefore it was characterized by a lower bound cost (no comorbidities) and an upper bound cost (comorbidities). It included the cost of antibiotics prescribed for 5 to 8 days of treatment. The cost was adjusted on the mean length hospitalization of the university Tours Hospital.

\section{Outcome cost}

For each outcome described on the decision tree, a cost per outcome was calculated by adding the different costs (genotype testing, chemotherapy, hospitalization for FN). The cost of hospitalization for FN was estimated with a lower and an upper bound. The outcome cost was estimated by multiplying the cost per outcome by the corresponding probability. The cost of the strategy (with lower and upper bounds) was calculated by adding all the outcome costs.

\section{Sensitivity analysis}

To determine the robustness of our results, a probabilistic sensitivity analysis was conducted by varying the value of some parameters of the model $\mathrm{v}$ while holding some others fixed. Changing the prevalence of haematological outcomes for the "no genotyping strategy" (22) as well as for the "genotyping strategy" and the prevalence of genotypes (23) allowed us to assess the effectiveness of the genotyping screening for different "at risk" populations (table 1). 
Table 1. Parameters of the sensitivity analysis.

\begin{tabular}{|c|c|c|c|c|c|c|}
\hline \multirow[b]{2}{*}{ Strategy } & & \multicolumn{2}{|c|}{ Prevalence } & \multicolumn{2}{|c|}{ Outcome } & \multirow[b]{2}{*}{ Data source } \\
\hline & & $\begin{array}{l}\text { Initial } \\
\text { value } \\
(\%) \\
\end{array}$ & $\begin{array}{c}\text { Varied } \\
\text { value } \\
(\%) \\
\end{array}$ & $\begin{array}{c}\text { Initial } \\
\text { value } \\
(\%) \\
\end{array}$ & $\begin{array}{c}\text { Varied } \\
\text { value } \\
(\%) \\
\end{array}$ & \\
\hline $\begin{array}{l}\text { No genotyping } \\
\text { strategy }\end{array}$ & & & & & & Fuchs C. 2007 \\
\hline Hematologic toxicity & $\begin{array}{l}\text { No } G+T \\
\text { No } G+\text { NP } 3 / 4 \\
\text { No G + FN }\end{array}$ & $\begin{array}{r}71.8 \\
21.8 \\
6.4 \\
\end{array}$ & $\begin{array}{r}53.3 \\
43.1 \\
3.6 \\
\end{array}$ & & & \\
\hline Genotyping strategy & & & & & & Roth AD. 2008 \\
\hline Genotype & $\begin{array}{l}\text { G 6/6 } \\
\text { G 6/7 } \\
\text { G 7/7 }\end{array}$ & $\begin{array}{c}42.5 \\
47.9 \\
9.6\end{array}$ & $\begin{array}{l}44 \\
43 \\
13\end{array}$ & $\begin{array}{c}71.8 \\
21.8 \\
6.4\end{array}$ & $\begin{array}{c}53.3 \\
43.1 \\
3.6\end{array}$ & \\
\hline Hematologic toxicity & $\begin{array}{l}\mathrm{G} 6 / 6+\mathrm{T} \\
\mathrm{G} 6 / 6+\mathrm{NP} 3 / 4 \\
\mathrm{G} 6 / 6+\mathrm{FN} \\
\mathrm{G} 6 / 7+\mathrm{T} \\
\mathrm{G} 6 / 7+\mathrm{NP} 3 / 4 \\
\mathrm{G} 6 / 7+\mathrm{FN}\end{array}$ & $\begin{array}{c}90.3 \\
9.7 \\
0 \\
60 \\
25.7 \\
14.3\end{array}$ & $\begin{array}{c}70.4 \\
25.5 \\
4.1 \\
70.0 \\
25.9 \\
4.1 \\
\end{array}$ & $\begin{array}{c}38.4 \\
4.1 \\
0 \\
28.7 \\
12.3 \\
6.9 \\
\end{array}$ & $\begin{array}{c}30.9 \\
11.2 \\
1.8 \\
30.1 \\
11.1 \\
1.8\end{array}$ & \\
\hline
\end{tabular}

\section{RESULTS}

The cost of the genotyping test per patient included the cost of laboratory equipment redemption $(€ 14)$, the cost of the laboratory staff $(€ 30)$, and the cost of reagents for genotyping $(€$ 27). Therefore, the cost of genotyping test per patient was $€ 71$.

A day-care chemotherapy hospitalization cost was $€ 353.0$ to which was added the cost of expensive anticancer drugs (table 2), for a final cost of $€ 1033.0$ for the FOLFIRI regimen, $€$ 913.0 for the FOLFIRI regimen $75 \%$ and $€$ 1245.4 for the FOLFOX regimen. The cost of hospitalisation for $\mathrm{FN}$ at the low bound
(16M04V) was $€ 1448.9$ while 3 times higher with the high bound (16M04W), with a cost of $€ 4$ 126.9 .

The outcomes costs described on the decision tree are detailed in table 3. This allowed us to assess the cost of the two strategies and to calculate the CE ratio. The effectiveness of genotyping screening was $91 \mathrm{FN}$ avoided. It was estimated by the difference of FN occurring in the "no genotyping strategy" (64 FN) and those avoided in the "genotyping strategy" (96 FN avoided in patients with the 7/7 genotype and 69 $\mathrm{FN}$ occurring in the other patients).

Table 2. Cost of irinotecan and oxaliplatine for FOLFIRI and FOLFOX regimen

\begin{tabular}{|c|c|c|c|c|c|c|}
\hline $\begin{array}{l}\text { Anticancer drug } \\
\text { (regimen) }\end{array}$ & $\begin{array}{l}\text { Posolgy } \\
\left(\mathrm{mg} / \mathrm{m}^{2}\right)\end{array}$ & $\begin{array}{l}\text { Dose for one } \\
\text { course (mg) }\end{array}$ & $\begin{array}{c}\text { Unit } \\
\text { Quantity } \\
\text { (mg) }\end{array}$ & $\begin{array}{l}\text { Number of } \\
\text { Units needed }\end{array}$ & $\begin{array}{c}\text { Unit Cost } \\
(€)\end{array}$ & $\begin{array}{c}\text { Unit Course } \\
\text { Cost (€) }\end{array}$ \\
\hline irinotecan & 180.0 & 333.0 & 100 & 3 & 200.0 & 68.0 \\
\hline (FOLFIRI) & & & 40 & 1 & 80.0 & \\
\hline Irinotecan $75 \%$ & 135.0 & 249.7 & 100 & 2 & 200.0 & 560.0 \\
\hline (FOLFIRI 75\%) & & & 40 & 2 & 80.0 & \\
\hline $\begin{array}{l}\text { Oxaliplatine } \\
\text { (FOLFOX) }\end{array}$ & 100.0 & 185.0 & 100 & 2 & 446.2 & 892.4 \\
\hline
\end{tabular}


Table 3 Direct costs and outcome costs for genotyping screening strategy in patients undergoing irinotecan therapy for metastatic colorectal cancer (1000 patients per strategy)

\begin{tabular}{|c|c|c|c|c|c|c|c|c|}
\hline Outcome & & $\begin{array}{c}\text { Cost per } \\
\text { genotyping test } \\
(€) \\
\end{array}$ & $\begin{array}{l}\text { Cost per chemotherapy } \\
\text { hospitalization }(€)\end{array}$ & $\begin{array}{c}\text { Cost per febrile } \\
\text { neutropenia } \\
\text { hospitalization* }(€)\end{array}$ & $\begin{array}{c}\text { Cost per } \\
\text { outcome }(€)\end{array}$ & $\begin{array}{c}\text { Outcome } \\
\text { probability }\end{array}$ & $\begin{array}{c}\text { Outcome } \\
\text { cost per } \\
\text { patient }(€)\end{array}$ & $\begin{array}{c}\text { Number of } \\
\text { febrile } \\
\text { neutropenia } \\
\end{array}$ \\
\hline \multicolumn{9}{|l|}{ No genotyping strategy } \\
\hline No G + T + FOLFIRI & & - & 1033.0 & 0.0 & 1033.0 & 0.718 & 741.7 & \\
\hline No G + NP 3/4 + FOLFIRI 75\% & & - & 913.0 & 0.0 & 913.0 & 0.218 & 199.0 & \\
\hline \multirow[t]{2}{*}{ No G + FN + Hosp + FOLFOX ${ }^{1}$} & low & - & 1245.4 & 1448.9 & 2694.3 & 0.064 & 172.4 & 64 \\
\hline & high & - & 1245.4 & 4126.9 & 5372.3 & 0.064 & 343.8 & 64 \\
\hline \multirow[t]{2}{*}{ Total no genotyping strategy } & low & & - & - & - & 1.0 & 1113.2 & \\
\hline & high & & - & - & - & 1.0 & 1284.6 & \\
\hline
\end{tabular}

\section{Genotyping strategy}

\begin{tabular}{|c|c|c|c|c|c|c|c|c|}
\hline G 6/6 + T + FOLFIRI & & 71.0 & 1033.0 & 0.0 & 1104.0 & 0.384 & 423.9 & \\
\hline G 6/6 + NP 3/4 + FOLFIRI 75\% & & 71.0 & 913.0 & 0.0 & 984.0 & 0.041 & 40.3 & \\
\hline \multirow[t]{2}{*}{$\mathrm{G} 6 / 6+\mathrm{FN}+\mathrm{Hosp}+\mathrm{FOLFOX}^{1}$} & low & 71.0 & 1245.4 & 1448.9 & 2765.3 & 0.0 & 0.0 & \\
\hline & high & 71.0 & 1245.4 & 4126.9 & 5443.3 & 0.0 & 0.0 & \\
\hline G 6/7 + T + FOLFIRI & & 71.0 & 1033.0 & 0.0 & 1104.0 & 0.287 & 316.8 & \\
\hline G $6 / 7+$ NP $3 / 4+$ FOLFIRI $75 \%$ & & 71.0 & 913.0 & 0.0 & 984.0 & 0.123 & 121.0 & \\
\hline \multirow[t]{2}{*}{ G $6 / 7+\mathrm{FN}+$ Hosp $^{2}$ FOLFOX $^{1}$} & low & 71.0 & 1245.4 & 1448.9 & 2765.3 & 0.069 & 190.8 & 69 \\
\hline & high & 71.0 & 1245.4 & 4126.9 & 5443.3 & 0.069 & 375.6 & 69 \\
\hline G7/7 + T + FOLFIRI & & 71.0 & 1033.0 & 0.0 & 1104.0 & 0.096 & 106.0 & 96 avoided \\
\hline \multirow[t]{2}{*}{ Total genotyping strategy } & low & & - & - & - & 1.0 & 1198.9 & \\
\hline & high & & - & - & - & 1.0 & 1383.7 & \\
\hline
\end{tabular}

${ }^{1}$ Hospitalization cost estimated with a low and high bound cost corresponding to patients without or with comorbidities. 
As shown in table 4, the low bound outcome cost per patient for the "genotyping strategy" was $€ 1198.9$ versus $€ 1113.2$ for the "no genotyping strategy". The high bound outcome cost per patient was respectively $€ 1383.7$ and $€ 1284$. Therefore the "genotyping strategy" cost to avoid one FN per 1000 patients event (ICER) was $€$ 942.8 to 1090.1 .

The sensitivity analysis took into account changes in prevalence (table 5). In a one way sensitivity analysis, and if considering the haematological toxicity higher (22) in the "no genotyping strategy", the $\mathrm{CE}$ ratio per patient was then twice higher as the ratio observed with our model. On the contrary, the CE ratio was decreasing when haematological toxicity was lower (23) in the "genotyping strategy". The combination of these two hypothesis estimated that "genotyping strategy" cost to avoid one FN event was $€ 733.4$ to 726.6 .

Table 4 Cost effectiveness analysis of genotyping screening strategy in patients undergoing irinotecan therapy for metastatic colorectal cancer (1000 patients per strategy)

\begin{tabular}{|c|c|c|c|c|c|}
\hline \multirow[t]{2}{*}{ Strategy } & \multirow{2}{*}{$\begin{array}{c}\text { Strategy } \\
\text { cost }(€)\end{array}$} & \multicolumn{2}{|c|}{ Strategy cost difference $(€)$} & \multirow{2}{*}{$\begin{array}{l}\text { Effectiveness }{ }^{a} \\
\text { (FN avoided) }\end{array}$} & \multirow{2}{*}{$\begin{array}{c}\text { ICER } \\
(€)\end{array}$} \\
\hline & & per patient & $\begin{array}{l}\text { for } 1000 \\
\text { patients }\end{array}$ & & \\
\hline Low bound ${ }^{\mathrm{b}}$ & & 85.8 & 85800 & & +942.8 \\
\hline Genotyping strategy & 1198.9 & & & 91 & \\
\hline No genotyping strategy & 1113.2 & & & & \\
\hline High bound ${ }^{\mathrm{b}}$ & & 99.2 & 99200 & & +1090.1 \\
\hline Genotyping strategy & 1383.7 & & & 91 & \\
\hline No genotyping strategy & 1284.6 & & & & \\
\hline
\end{tabular}

Table 5 Sensibility analysis of cost effectiveness analysis of genotyping screening strategy in patients undergoing irinotecan therapy for metastatic colorectal cancer (1000 patients per strategy)

\begin{tabular}{|c|c|c|c|}
\hline Prevalence & & $\begin{array}{l}\text { Effectiveness } \\
\text { (FN avoided) }\end{array}$ & $\begin{array}{c}\text { Cost effectiveness ratio } \\
\text { per patient }(€)\end{array}$ \\
\hline $\begin{array}{l}1-\text { Varied for no genotyping strategy } \\
\text { (Fuchs } 2007,[3] \text { ) }\end{array}$ & $\begin{array}{l}\text { Low bound } \\
\text { High bound }\end{array}$ & $\begin{array}{l}80 \\
80\end{array}$ & $\begin{array}{l}+1973.3 \\
+3078.0\end{array}$ \\
\hline $\begin{array}{l}2-\text { Varied for genotyping strategy (Roth } \\
2008,[14] \text { ) }\end{array}$ & $\begin{array}{l}\text { Low bound } \\
\text { High bound }\end{array}$ & $\begin{array}{l}158 \\
158\end{array}$ & $\begin{array}{l}+147.3 \\
-332.9\end{array}$ \\
\hline $\begin{array}{l}3 \text { - Simultaneous change of previous } \\
\text { prevalence ( } 1 \text { and } 2)\end{array}$ & $\begin{array}{l}\text { Low bound } \\
\text { High bound }\end{array}$ & $\begin{array}{l}130 \\
130\end{array}$ & $\begin{array}{l}+733.4 \\
+726.6\end{array}$ \\
\hline
\end{tabular}




\section{DISCUSSION}

Irinotecan has significant side effects, including myelosuppression and delayed-type diarrhea. The UGT1A1*28 allele has also been associated with the risk of neutropenia. Our study shows that genotyping patients is a cost-effective strategy from a hospital perspective when CSF is administered to $7 / 7$ subjects. The ICER, i.e. the cost to avoid one neutropenia per 1000 patients was $€ 942.8$ to 1090 , without any risk of reducing efficacy as irinotecan is administered as full dose.

In the current economic context, proof of cost-effectiveness should precede the translation of a new therapeutic strategy into routine clinical practice. To our knowledge only two studies including economic considerations for a genotyping strategy in patients undergoing irinotecan therapy were conducted $(15,24)$. Both were based on a healthcare payer's perspective and evaluated life-years gained or quality of life weights. The first study compared two strategies in patients treated with second-line high dose irinotecan monotherapy, i.e. dose reduction or prophylactic use of CSF in patients bearing the $7 / 7$ genotype (24). They found that a $20 \%$ reduced dosage was cost-saving and more effective in Caucasian patients. Similarly, Gold et al. concluded that genotyping was cost-effective when a $25 \%$ dose reduction in patients homozygotes for the $* 28$ allele was used, but acknowledged that this procedure may reduce efficacy in these patients (15). A recent study showed that patients with the UGT1A1 $6 / 6$ or $6 / 7$ genotypes can tolerate much higher doses of irinotecan in the FOLFIRI regimen than the current one (25-27). The safe dose of irinotecan in $7 / 7$ patients remains an open question but concerns about decreased efficacy as a consequence of dose reduction are worth considering.

Our strategy, based on prophylactic administration of CSF and full dose of irinotecan, prevents any loss of efficacy while avoiding toxicity. Contrary to Obradovich et al., we found that this strategy was cost-effective. A very different approach was used for cost estimation in their study than in ours. The present study was conducted from a hospital point of view and only considered the two first courses when Obradovich's study considered the healthcare payer's perspective over the expected treatment duration. Our choice to limit our study to two courses of chemotherapy was based on the fact that severe neutropenia occurs primarily in the first two courses of chemotherapy (28). As we considered that the primary objective of UGT1A1 genotyping is tolerance of the first cycle, knowledge of the genotype would only influence the initial choice of treatment (full-dose with or without CFS), subsequent clinical management of patients being primarily guided by patient's tolerance. In such case, no difference is expected between the two strategies (genotyping or not) after the two first cycles. Although indirect, the number of FN avoided may reflect gained life, as it has been shown that $\mathrm{FN}$ is associated with death (5). However, it is acknowledged that comparison with other health technologies that may report cost per quality-adjusted life-year (QALY) or cost per life-year gain (LYG), are difficult. To conduct an analysis that generated cost per QALY or LYG estimates would require the differences between each treatment strategy to be analyzed. We did not opt for a full ecomonic model in our analysis as our primary intention was to evaluate whether or not UGT1A1 genotype testing would be an efficient use of additional resources from the hospital.

Only few studies were used to build our model as most of the available data were not associated with complete informationof polymorphisms prevalence or FN incidence. In order to be representative of our patients and to limit variability, only studies conducted on Caucasian populations were considered. It is wellknown that interethnic variability in UGT1A1 7/7 genotype frequency exists $(10,29)$ and acts as a confounding factor in cost-effectiveness evaluation of UGT1A1*28 genotyping (24). Finally, we also assumed $100 \%$ efficacy of CSF therapy, thus inflating our estimates of neutropenic events avoided, if efficacy is in fact lower.

Our costs did not include the cost of CSF as this drug was not provided by the hospital. Conversely, we also excluded indirect and intangible costs which are respectively the cost of the negatives consequences and the social and psychological consequences induced by the pathology. This may be critical as Cosler et al., showed that taking into account theses costs could double the medical cost for FN (30). In such a case, the prophylaxis strategy with genotyping could become even less expensive than the no genotyping strategy.

Our work was based on the hypothesis that toxicity depended mainly on the UGT1A $1 * 28$ polymorphism. In Rouits et al. study conducted on a cohort of 75 patients treated with $180 \mathrm{mg} / \mathrm{m}^{2}$ 
irinotecan every 14 days, a significant link between UGT1A $1 * 28$ homozygosity and irinotecan toxicity was shown (13). Innocenti et al. and McLeod et al. also showed that the risk of neutropenia was higher in patients receiving chemotherapy with $350 \mathrm{mg} / \mathrm{m}^{2}$ of irinotecan every 3 weeks $(12,31)$. On the contrary, Carlini et al. did not found any correlation between the UGT1A1*28 polymorphism and irinotecan toxicity using a $125 \mathrm{mg} / \mathrm{m}^{2}$ weekly dose.

It is currently acknowledged that the impact of UGT1A $1 * 28$ polymorphism on the incidence of grade 3-4 neutropenia depends on the dose of irinotecan administered (14). From the three studies providing data at an intermediate dose of $180 \mathrm{mg} / \mathrm{m}^{2}$ biweekly, all found an association between UGT1A1828 and neutropenia $(13,32)$, the association being only relevant for the first cycle and not throughout the whole treatment period in Toffoli's study (28).

Irinotecan toxicity's can also be affected by other polymorphisms. Indeed, the pharmacokinetics of irinotecan and its metabolites includes other efflux proteins such as the glycoprotein $\mathrm{P}$, the BCRP (Brain Cancer Resistance Protein) or multidrug resistance related proteins (MRP1, MRP2), each affected by genetic polymorphisms (10). However, the polymorphism of these proteins implicated in the biliary secretion of irinotecan, is translated into increased digestive toxicity, as shown by De Jong et al. for the $A B C C 2$ polymorphism (33).

Genotyping patients for UGT1A1*28 before irinotecan administration is a cost-effective strategy for the hospital with the hypothesis that the G7/7 patients under CSF do not present any $\mathrm{NF}$. We propose that UGT1A $1 * 28$ screening before treatment initiation could be implemented in routine use. However, given that it is a statistical model based on literature, these findings require prospective evaluation when this strategy is used in patient care.

\section{ACKNOWLEDGMENTS}

The author declare that they have not received any specific financial support for performing the present study nor was any financial support provided by any company involved in the production of UGT1A1 test kits.

\section{REFERENCES}

1. Meyerhardt J. A., Mayer R. J. Systemic therapy for colorectal cancer. N Engl J Med 2005;352(5):476-87.

2. Douillard J. Y. Irinotecan and high-dose fluorouracil/leucovorin for metastatic colorectal cancer. Oncology (Williston Park) 2000;14(12 Suppl 14):51-5.

3. Giacchetti S., Perpoint B., Zidani R., Le Bail N., Faggiuolo R., Focan C., Chollet P., Llory J. F., Letourneau Y., Coudert B., Bertheaut-Cvitkovic F., Larregain-Fournier D., Le Rol A., Walter S., Adam R., Misset J. L., Levi F. Phase III multicenter randomized trial of oxaliplatin added to chronomodulated fluorouracil-leucovorin as first-line treatment of metastatic colorectal cancer. J Clin Oncol 2000;18(1):136-47.

4. Ozer H., Armitage J. O., Bennett C. L., Crawford J., Demetri G. D., Pizzo P. A., Schiffer C. A., Smith T. J., Somlo G., Wade J. C., Wade J. L., 3rd, Winn R. J., Wozniak A. J., Somerfield M. R. 2000 update of recommendations for the use of hematopoietic colony-stimulating factors: evidence-based, clinical practice guidelines. American Society of Clinical Oncology Growth Factors Expert Panel. J Clin Oncol 2000;18(20):3558-85.

5. Caggiano V., Weiss R. V., Rickert T. S., LindeZwirble W. T. Incidence, cost, and mortality of neutropenia hospitalization associated with chemotherapy. Cancer 2005;103(9):1916-24.

6. Crawford J. Improving the management of chemotherapy-induced neutropenia. J Support Oncol 2004;2(2 Suppl 2):36-9.

7. Chabot G. G. Clinical pharmacokinetics of irinotecan. Clin Pharmacokinet 1997;33(4):245-59.

8. Cote J. F., Kirzin S., Kramar A., Mosnier J. F., Diebold M. D., Soubeyran I., Thirouard A. S., Selves J., Laurent-Puig P., Ychou M. UGT1A1 polymorphism can predict hematologic toxicity in patients treated with irinotecan. Clin Cancer Res 2007;13(11):3269-75.

9. Iyer L., Das S., Janisch L., Wen M., Ramirez J., Karrison T., Fleming G. F., Vokes E. E., Schilsky R. L., Ratain M. J. UGT1A1*28 polymorphism as a determinant of irinotecan disposition and toxicity. Pharmacogenomics J 2002;2(1):43-7.

10. Fujiwara Y., Minami H. An overview of the recent progress in irinotecan pharmacogenetics. Pharmacogenomics 2010;11(3):391-406.

11. Fakih M. G., Ross M. E., Starostik P. Increased frequency of uridine diphosphate glucuronosyltransferase $1 \mathrm{~A} 1 \quad 7 / 7$ in patients experiencing severe irinotecan-induced toxicities. Clin Colorectal Cancer 2007;6(8):583-7.

12. Innocenti F., Undevia S. D., Iyer L., Chen P. X., Das S., Kocherginsky M., Karrison T., Janisch L., Ramirez J., Rudin C. M., Vokes E. E., Ratain M. J. Genetic variants in the UDP- 
glucuronosyltransferase 1A1 gene predict the risk of severe neutropenia of irinotecan. J Clin Oncol 2004;22(8):1382-8.

13. Rouits E., Boisdron-Celle M., Dumont A., Guerin O., Morel A., Gamelin E. Relevance of different UGT1A1 polymorphisms in irinotecan-induced toxicity: a molecular and clinical study of 75 patients. Clin Cancer Res 2004;10(15):5151-9.

14. Hoskins J. M., Goldberg R. M., Qu P., Ibrahim J. G., McLeod H. L. UGT1A1*28 genotype and irinotecan-induced neutropenia: dose matters. J Natl Cancer Inst 2007;99(17):1290-5.

15. Gold H. T., Hall M. J., Blinder V., Schackman B. R. Cost effectiveness of pharmacogenetic testing for uridine diphosphate glucuronosyltransferase 1A1 before irinotecan administration for metastatic colorectal cancer. Cancer 2009;115(17):3858-67.

16. Aapro M. S., Cameron D. A., Pettengell R., Bohlius J., Crawford J., Ellis M., Kearney N., Lyman G. H., Tjan-Heijnen V. C., Walewski J., Weber D. C., Zielinski C. EORTC guidelines for the use of granulocyte-colony stimulating factor to reduce the incidence of chemotherapy-induced febrile neutropenia in adult patients with lymphomas and solid tumours. Eur J Cancer 2006;42(15):2433-53.

17. Smith T. J., Khatcheressian J., Lyman G. H., Ozer H., Armitage J. O., Balducci L., Bennett C. L., Cantor S. B., Crawford J., Cross S. J., Demetri G., Desch C. E., Pizzo P. A., Schiffer C. A., Schwartzberg L., Somerfield M. R., Somlo G., Wade J. C., Wade J. L., Winn R. J., Wozniak A. J., Wolff A. C. 2006 update of recommendations for the use of white blood cell growth factors: an evidence-based clinical practice guideline. J Clin Oncol 2006;24(19):3187-205.

18. Anonymous. Recommendations from the EGAPP Working Group: can UGT1A1 genotyping reduce morbidity and mortality in patients with metastatic colorectal cancer treated with irinotecan? Genet Med 2009;11(1):15-20.

19. Beutler E., Gelbart T., Demina A. Racial variability in the UDP-glucuronosyltransferase 1 (UGT1A1) promoter: a balanced polymorphism for regulation of bilirubin metabolism? Proc Natl Acad Sci U S A 1998;95(14):8170-4.

20. Anonymous. US Food and Drug Administration: Irinotecan package insert. http://www.fda.gov/ohrms/dockets/dockets/05p04 96/05p-0496-cp00001-04-Attachment-03-vol1.pdf. In; 2005.

21. Tournigand C., Andre T., Achille E., Lledo G., Flesh M., Mery-Mignard D., Quinaux E., Couteau C., Buyse M., Ganem G., Landi B., Colin P., Louvet C., de Gramont A. FOLFIRI followed by FOLFOX6 or the reverse sequence in advanced colorectal cancer: a randomized GERCOR study. J Clin Oncol 2004;22(2):229-37.

22. Fuchs C. S., Marshall J., Mitchell E., Wierzbicki R., Ganju V., Jeffery M., Schulz J., Richards D.,
Soufi-Mahjoubi R., Wang B., Barrueco J. Randomized, controlled trial of irinotecan plus infusional, bolus, or oral fluoropyrimidines in first-line treatment of metastatic colorectal cancer: results from the BICC-C Study. J Clin Oncol 2007;25(30):4779-86.

23. Roth A. D., Estève J., Bouvier A. M. Is UGT1A $1 * 28$ homozygoty the strongest predictor for severe hematotoxicity in patients treated with 5-fluorouracil (5-FU)-irinotecan (IRI)? results of the PETACC3-EPRTC 40993-SAAK 60/00 trial comparing IRI/5-FU/folonic acid (FA) to 5-FU/FA in colon cancer patients. J Clin Oncol 2008;26(suppl):4036.

24. Obradovic M., Mrhar A., Kos M. Costeffectiveness of UGT1A1 genotyping in secondline, high-dose, once every 3 weeks irinotecan monotherapy treatment of colorectal cancer. Pharmacogenomics 2008;9(5):539-49.

25. Toffoli G., Cecchin E., Gasparini G., D'Andrea M., Azzarello G., Basso U., Mini E., Pessa S., De Mattia E., Lo Re G., Buonadonna A., Nobili S., De Paoli P., Innocenti F. Genotype-driven phase I study of irinotecan administered in combination with fluorouracil/leucovorin in patients with metastatic colorectal cancer. J Clin Oncol 2010;28(5):866-71.

26. Ducreux M., Ychou M., Seitz J. F., Bonnay M., Bexon A., Armand J. P., Mahjoubi M., MeryMignard D., Rougier P. Irinotecan combined with bolus fluorouracil, continuous infusion fluorouracil, and high-dose leucovorin every two weeks (LV5FU2 regimen): a clinical dose-finding and pharmacokinetic study in patients with pretreated metastatic colorectal cancer. J Clin Oncol 1999;17(9):2901-8.

27. Ychou M., Raoul J. L., Desseigne F., Borel C., Caroli-Bosc F. X., Jacob J. H., Seitz J. F., Kramar A., Hua A., Lefebvre P., Couteau C., Merrouche Y. High-dose, single-agent irinotecan as first-line therapy in the treatment of metastatic colorectal cancer. Cancer Chemother Pharmacol 2002;50(5):383-91.

28. Toffoli G., Cecchin E., Corona G., Russo A., Buonadonna A., D'Andrea M., Pasetto L. M., Pessa S., Errante D., De Pangher V., Giusto M., Medici M., Gaion F., Sandri P., Galligioni E., Bonura S., Boccalon M., Biason P., Frustaci S. The role of UGT1A $1 * 28$ polymorphism in the pharmacodynamics and pharmacokinetics of irinotecan in patients with metastatic colorectal cancer. J Clin Oncol 2006;24(19):3061-8.

29. Zhang A., Xing Q., Qin S., Du J., Wang L., Yu L., Li X., Xu L., Xu M., Feng G., He L. Intra-ethnic differences in genetic variants of the UGTglucuronosyltransferase 1A1 gene in Chinese populations. Pharmacogenomics J 2007;7(5):3338.

30. Cosler L. E., Calhoun E. A., Agboola O., Lyman G. H. Effects of indirect and additional direct costs on the risk threshold for prophylaxis with colony- 
stimulating factors in patients at risk for severe neutropenia from cancer chemotherapy. Pharmacotherapy 2004;24(4):488-94.

31. Mc Leod H., Parodi L., Sargent D. UGT1A1*28 toxicity and outcome in advanced colorectal cancer: results from trial N9741. J Clin Oncol 2006;24(18):151s.

32. Marcuello E., Altes A., Menoyo A., Del Rio E., Gomez-Pardo M., Baiget M. UGT1A1 gene variations and irinotecan treatment in patients with metastatic colorectal cancer. $\mathrm{Br} \mathrm{J}$ Cancer 2004;91(4):678-82.

33. de Jong F. A., Scott-Horton T. J., Kroetz D. L., McLeod H. L., Friberg L. E., Mathijssen R. H., Verweij J., Marsh S., Sparreboom A. Irinotecaninduced diarrhea: functional significance of the polymorphic ABCC2 transporter protein. Clin Pharmacol Ther 2007;81(1):42-9. 